\title{
Luminescence spectrum of 2-(2'-hydroxyphenyl)benzoxazole in the solid state
}

\author{
Syetov Y.
}

Department of Solid State Physics and Optoelectronics, Oles Gonchar Dnipropetrovsk National University, 72 Gagarin Ave., 49010 Dnipropetrovsk, Ukraine, e-mail: setov2003@yahoo.com

Received: 24.10 .2012

\begin{abstract}
We have found that the luminescence spectrum of 2-(2'-hydroxyphenyl)benzoxazole in its solid state includes only a band with a large Stokes shift assigned to a keto structure. Our quantum chemical calculations of the electronic structure of the molecule have demonstrated that restriction of the internal rotation increases quantum yield of the keto luminescence, while the luminescence with the normal Stokes shift can be quenched by the energy transfer.
\end{abstract}

Keywords: excited-state proton transfer, mixed molecular crystals, luminescence, density functional theory

PACS: $78.55 . \mathrm{Kz}$

UDC: $539.21,543.42$

\section{Introduction}

2-(2'-hydroxyphenyl)benzoxazole (HBO) is an intra-molecularly hydrogen-bonded compound that exhibits excited-state intramolecular proton transfer (ESIPT) upon photo-excitation. In HBO with an enol structure (see structure I in Fig. 1) in the ground state, the ESIPT occurs from a hydroxyl group to a heterocyclic nitrogen atom, resulting in a keto tautomer (see structure III in Fig. 1) [1]. It is known that the substances exhibiting the ESIPT have been probed for a variety of applications [2].

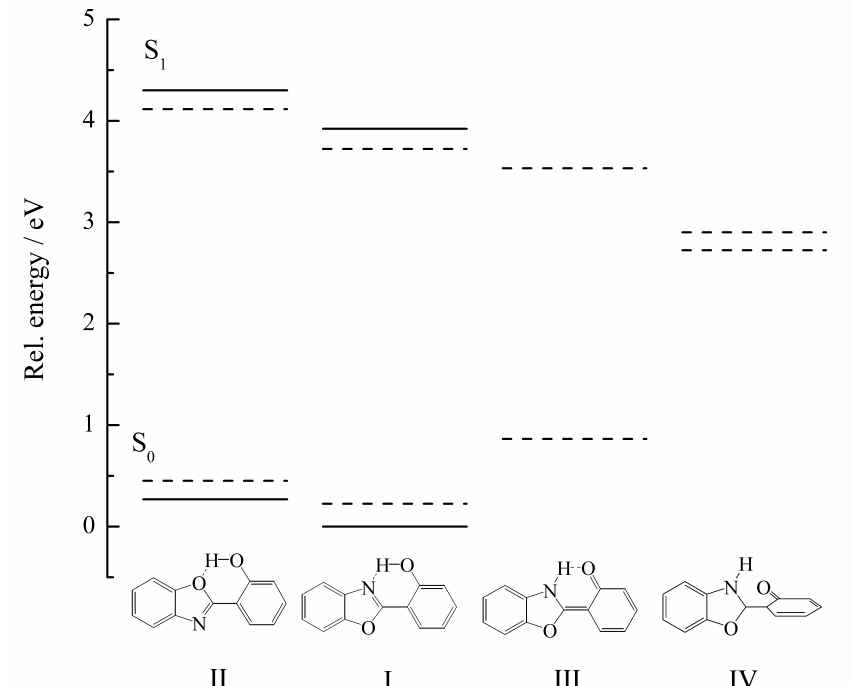

Fig. 1. Calculated electronic energy of rotameric and tautomeric species of an isolated HBO molecule. Solid and dashed lines represent the energies of structures optimised in the ground and first excited singlet states, respectively.

Ukr. J. Phys. Opt. 2013, Volume 14, Issue 1 
$\mathrm{HBO}$ is strongly luminescent in its crystalline state, with the quantum yield being equal to 0.42 . At the room temperature the quantum yield for its liquid solution is much less $(0.018)$ and depends on the viscosity of a solvent. The major radiationless channel is supposed to be large amplitude twisting of the molecule in its excited state $[1,3]$. HBO in its ground state can exist in two rotameric forms with intra-molecular hydrogen bonds (see structures I and II); only the structure with a hydrogen bond $\mathrm{OH} . . . \mathrm{N}$ undergoes the ESIPT and demonstrates fluorescence with a large Stokes shift (keto fluorescence). From the other hand, the rotamer II with the hydrogen bond $\mathrm{OH} . . . \mathrm{O}$ exhibits only the fluorescence with a normal Stokes shift $[1,4,5]$. A conformational disorder characterised by approximately equal numbers of the structures I and II has been reported for the HBO crystal basing on the X-ray measurements [6], though the studies for the IR spectra of solid-state HBO in the region of its intra-molecular vibrations have found no bands that could be assigned to vibrations of the $\mathrm{OH} . . . \mathrm{O}$ rotamers [7]. The fluorescence spectrum of $\mathrm{HBO}$ in the solid state has been reported only for the region of its keto fluorescence [3].

\section{Experimental and computational details}

HBO sample studied in this work was kindly provided by Prof. Anna Grabowska (the Institute of Physical Chemistry, Polish Academy of Sciences). The measurements for solution were performed with $\mathrm{CCl}_{4}$ (the concentration $1 \cdot 10^{-5} \mathrm{M}$ ). Polycrystalline powder was obtained using evaporation of $\mathrm{CCl}_{4}$ solution at the room temperature. The fluorescence spectra were recorded with a Jasny spectrofluorimeter [8], with the resolution of $4 \mathrm{~nm}$ at the room temperature. The excitation wavelength was $309 \mathrm{~nm}$. The structure, energy and oscillator strengths of vertical transitions, as well as the frequencies of harmonic vibrations were calculated with DFT and TDDFT methods implemented in the frame of GAMESS program $[9,10]$. A B3LYP functional and a 6-31G(d,p) basic set were used for the isolated molecules in their ground and first excited states. The potential energy surfaces were explored taking the $\mathrm{OH}$ distance and the averaged sum of the four dihedral angles (i.e., $\mathrm{CCCO}$ and $\mathrm{CCCN}$ angles) as driving coordinates for the proton transfer and the rotation, respectively. The other degrees of freedom were optimised. $\mathrm{C}_{\mathrm{s}}$ symmetry of the molecule was assumed for the proton transfer.

\section{Results and discussion}

The luminescence spectrum of $\mathrm{HBO}$ dissolved in $\mathrm{CCl}_{4}$ at the room temperature demonstrates an intense band with a maximum located at $504 \mathrm{~nm}$ and a weak band at $357 \mathrm{~nm}$. In the spectrum peculiar for the polycrystalline $\mathrm{HBO}$, only a band at $504 \mathrm{~nm}$ is observed, its position and shape being similar to those typical for the solution (see Fig. 2). The spectrum measured in $\mathrm{CCl}_{4}$ agrees with the results reported for the fluorescence spectra of HBO in non-polar solvents, where the band with a large Stokes shift has been assigned to the keto tautomer and the band with a normal Stokes shift to the rotamer with the $\mathrm{OH} . . . \mathrm{O}$ hydrogen bond $[4,5]$.

The relative energies of the ground and excited states of the structures I-III are shown in Fig. 1. The energy of the structure II in its ground state is calculated to be about $0.26 \mathrm{eV}$ higher than the energy of the most stable structure I. The energy barrier separating the structures I and II is evaluated to be about $0.64 \mathrm{eV}$; the rotamers undergo inter-conversion in solution and the number of molecules II estimated using the Boltzmann distribution is of the order of $10^{-5}$, when compared to the number of molecules I. Hence, low luminescence intensity for the molecules II in solution is caused by low concentration of $\mathrm{OH}$... O conformations in the ground state.

The calculations predict a single potential energy minimum that corresponds to the enol structure I in the ground state, while the keto structure III is unstable. Two minima have been 
found for the excited state. The calculations yield an asymmetric potential energy surface for the ESIPT (see Fig. 3). The barrier between the minima estimated as the energy of the saddle point is equal to $0.03 \mathrm{eV}$, while the enol structure $\mathrm{I}$ is found to be less stable than the planar keto structure III (by about $0.19 \mathrm{eV}$ ). Consideration of a zero-point vibrational energy eliminates the barrier; the energy of the saddle point is then $0.07 \mathrm{eV}$ lower than that of the enol structure I. The potential energy profiles for the ESIPT and for the ground-state back proton transfer demonstrate that, in the isolated $\mathrm{HBO}$ molecule, these processes occur as fast internal vibrational relaxations. The energy of the $0-0$ transition for the $\mathrm{OH}$... O rotamer II $(3.72 \mathrm{eV})$ is higher than the energy of the same transition for the most stable structure I $(3.57 \mathrm{eV})$, thus implying that the emission spectrum of the molecules II and the absorption spectrum of the molecules I are overlapped.

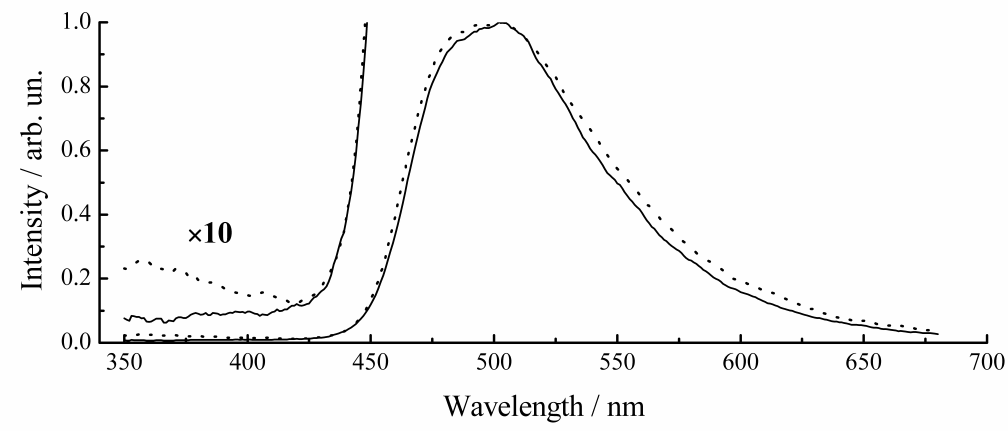

Fig. 2. Luminescence spectra of HBO in the solid state (solid line) and solution (dotted line). The spectra are normalised to the intensities achieved in the maximums.

The planar keto structure III is found to correspond to a transition state rather than a minimum (see Fig. 3). Internal rotation leads to the twisted structure IV with almost perpendicular benzoxazole and phenolic moieties. This is accompanied by decreasing energy gap between the ground and excited states (down to $0.17 \mathrm{eV}$ at the minimum). A low gap value at the minimum indicates a possibility that the potential energy surfaces of the ground and the first excited states intersect each other in the proximity of the minimum, and an efficient radiationless decay of the excited state is possible.
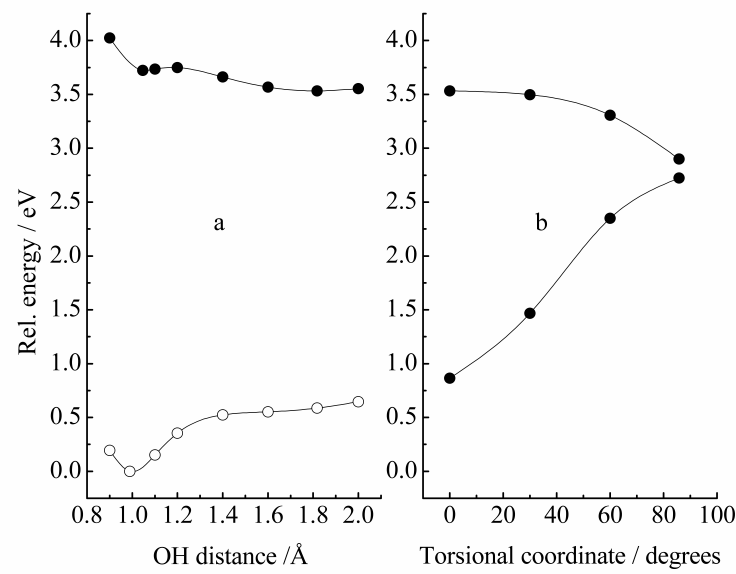

Fig 3. Minimum energy curves for $\mathrm{OH}$ stretching (a) and internal rotation (b).Solid and open circles correspond to geometries optimised in the excited and ground states, respectively.

According to the X-ray data, HBO molecules form stacked structures in their crystalline state, with the inter-molecular distance of $3.53 \AA$ [6]. The internal rotation that provides perpen- 
dicular orientations of the benzoxazole and phenolic moieties is expected to be suppressed by crystal packing. The same factor prevents inter-conversion of the structures I and II in the ground state and a radiationless decay of the excited state of the keto structure III. Restriction of this rotation causes increasing quantum yield of the keto luminescence. A short distance between the molecules in the crystal and spectral overlapping of the luminescence and the absorption enables the energy transfer of both absorption and radiationless resonance mechanisms [11]. The structure II in its excited state is calculated to have the energy about $0.39 \mathrm{eV}$ higher than that of the structure I. The energy transfer from the molecules II to the molecules I quenches the emission of the former, whereas the molecules I undergo the ESIPT, yielding a large Stokes shift of the luminescence band.

\section{Conclusions}

The luminescence spectrum of HBO in its solid state has been found to comprise only the band corresponding to the keto structure. This suggests low concentration of the rotamer with the $\mathrm{OH} . . . \mathrm{O}$ hydrogen bonds, which exhibit luminescence with a normal Stokes shift. A small number of the $\mathrm{OH} . . . \mathrm{O}$ structures agrees with equilibrium distribution expected for the isolated molecules, though the intensity of the luminescence is dependent on radiationless processes, too. The quantum chemical calculations show that the emission of the $\mathrm{OH}$...O rotamers can be quenched by the energy transfer, whereas the keto emission is enhanced by restricting large-amplitude twisting of the molecule.

\section{References}

1. Ormson S M and Brown R G, 1994. Excited state intramolecular proton transfer. Part 1: ESIPT to nitrogen. Prog. Reaction Kinetics. 19: 45-91.

2. Kwon J E and Park S Y, 2011. Advanced organic optoelectronic materials: harnessing excitedstate intramolecular proton transfer (ESIPT). Process. Adv. Mater. 23: 3615-3642.

3. Williams D L and Heller A, 1970. Intramolecular proton transfer reaction in excited fluorescent compounds. J. Phys. Chem. 24: 4473-4480.

4. Woolfe G J, Melzig M, Schneider S and Dörr F, 1983. The role of tautomeric and rotameric species in the photophysics of 2-(2'-hydroxyphenyl)benzoxazole. Chem. Phys. 77: 213-221.

5. Wang H, Zhang H, Abu-Zied O K, Yu C, Romesberg F E and Glasbeek M, 2003. Femtosecond fluorescence upconversion studies of excited-state proton transfer dynamics in 2-(2'-hydroxyphenyl)benzoxazole (HBO) in solution and DNA. Chem. Phys. Lett. 367: 599-608.

6. Tong Y P, 2005. 2-(2-Hydroxyphenyl)-1,3-benzoxazole. Acta Cryst. E. 61: o3076-o3078.

7. Syetov $Y$ and Vdovin A, 2010. Infrared spectra of benzoxazoles exhibiting excited state proton transfer. Vib. Spectrosc. 53: 146-150.

8. Jasny J, 1978. Multifunctional spectrofluorimetric system. J. Lumin. 17: 149-173.

9. Schmidt M W, Baldridge K K, Boatz J A, Elbert S T, Gordon M S, Jensen J H, Koseki S, Matsunaga N, Nguyen K A, Su S J, Windus T L, Dupuis M and Montgomery J A, 1993. General atomic and molecular electronic structure system. J. Comput. Chem. 14: 1347-1363.

10. Gordon M C and Schmidt M W. Advances in electronic structure theory: GAMESS a decade later. Chapter 41, in Theory and Applications of Computational Chemistry, the First Forty Years. Ed. by Dykstra C E, Frenking G, Kim K S and Scuseria G E. Amsterdam: Elsevier (2005) pp. 1167-1189.

11. Agranovich V M and Galanin M D. Electronic excitation energy transfer in condensed matter. Amsterdam: North-Holland (1982). 
Syetov Y., 2013. Luminescence spectrum of 2-(2'-hydroxyphenyl)benzoxazole in the solid state. Ukr.J.Phys.Opt. 14: $1-5$

Анотація. Встановлено, щзо спектр люмінесцениії 2-(2'-гідроксіфеніл)бензоксазолу у твердому стані містить лише смугу з великим стоксовим зсувом, яку віднесено до кето структури. Квантовохімічні розрахунки електронної структури ізольованої молекули показують, щзо обмеження внутрішнього обертання збільшує квантовий вихід кето люмінесиениії, тод $i$ як випромінювання з нормальним стоксовим зсувом може гаситися через перенесення енергіï. 